\title{
Quality of life in overweight (obese) and normal- weight women with polycystic ovary syndrome
}

\author{
This article was published in the following Dove Press journal: \\ Patient Preference and Adherence \\ 2 March 2017 \\ Number of times this article has been viewed
}

\author{
Annalisa Panico' \\ Giovanni Messina ${ }^{2,3}$ \\ Gelsy Arianna Lupoli' \\ Roberta Lupoli' \\ Marianna Cacciapuoti ${ }^{1}$ \\ Fiorenzo Moscatelli² \\ Teresa Esposito ${ }^{3}$ \\ Ines Villano 3 \\ Anna Valenzano ${ }^{2}$ \\ Vincenzo Monda ${ }^{3}$ \\ Antonietta Messina ${ }^{3}$ \\ Francesco Precenzano ${ }^{4}$ \\ Giuseppe Cibelli \\ Marcellino Monda ${ }^{3}$ \\ Giovanni Lupoli' \\ 'Department of Clinical Medicine \\ and Surgery, University of Napoli \\ Federico II, Naples, Italy; ${ }^{2}$ Department \\ of Clinical and Experimental Medicine, \\ University of Foggia, Foggia, Italy; \\ ${ }^{3}$ Department of Experimental \\ Medicine, Second University of \\ Naples, Naples, Italy; ${ }^{4}$ Department \\ of Mental and Physical Health, \\ and Preventive Medicine, Child \\ and Adolescent Neuropsychiatry \\ Unit, Second University of Naples, \\ Naples, Italy
}

Objective: Polycystic ovary syndrome (PCOS) is characterized by phenotypic heterogeneity and has a wide variety of consequences. Approximately half of women with PCOS are overweight or obese, and their obesity may be a contributing factor to PCOS pathogenesis through different mechanisms. The aim of this study was to evaluate if PCOS alone affects the patients' quality of life and to what extent obesity contributes to worsen this disease.

Design: To evaluate the impact of PCOS on health-related quality-of-life (HRQoL), 100 Mediterranean women with PCOS (group A), 50 with a body mass index (BMI) $>25 \mathrm{~kg} / \mathrm{m}^{2}$ (group $\mathrm{A}_{1}$ ) and 50 with BMI $<25 \mathrm{~kg} / \mathrm{m}^{2}$ (group $\mathrm{A}_{2}$ ), were recruited. They were evaluated with a specific combination of standardized psychometric questionnaires: the Symptom Checklist-90 Revised, the 36-Item Short-Form Health Survey, and the Polycystic Ovary Syndrome Questionnaire. The patients were compared with a normal-weight healthy control group of 40 subjects (group B). Another control group of 40 obese healthy women (group C) was used to make a comparison with PCOS obese patients $\left(\mathrm{A}_{1}\right)$.

Results: Our results showed a considerable worsening of HRQoL in PCOS patients (A) compared with controls (B). In addition, patients with PCOS and BMI $>25\left(\mathrm{~A}_{1}\right)$ showed a significant and more marked reduction in scores, suggesting a lower quality of life, compared with controls (B) and with normal-weight PCOS patients $\left(\mathrm{A}_{2}\right)$.

Conclusion: PCOS is a complex disease that alone determines a deterioration of HRQoL. The innovative use of these psychometric questionnaires in this study, in particular the PCOS questionnaire, has highlighted that obesity has a negative effect on HRQoL. It follows that a weight decrease is associated to phenotypic spectrum improvement and relative decrement in psychological distress. Keywords: polycystic ovary syndrome, obesity, normal-weight, health-related quality-of-life, psychological disturbances

\section{Introduction}

Polycystic ovary syndrome (PCOS) is a common, endocrine-metabolic disorder affecting premenopausal women and has a prevalence ranging from $5 \%$ to $10 \%$ among Mediterranean women, ${ }^{1}$ but its pathophysiology has not yet been fully understood. ${ }^{2}$ PCOS is characterized by oligo-anovulatory menstrual cycles, larger and micropolycystic ovaries, and a variable degree of hyperandrogenism, ${ }^{3}$ and it is usually associated with metabolic disorders (insulin resistance, hyperinsulinemia, obesity, dyslipidemia, diabetes mellitus type 2 , etc) and higher cardiovascular risk. ${ }^{4,5}$

Approximately half of women with PCOS are overweight or obese. ${ }^{6-15}$ The pathogenetic role of obesity can affect different mechanisms, of which the most important is the hyperinsulinemic state given that insulin can stimulate ovary androgen secretion and play an important role in the metabolism of androgens and their transport to peripheral tissues. ${ }^{16,17}$ Abdominal fat distribution in obese PCOS women
Correspondence: Giovanni Messina Department of Clinical and Experimental Medicine, University of Foggia, Via L Pinto, 7I I 22 Foggia, Italy

Tel +39 8I 5665804

Fax +39 8I 5665844

Email gianni.messina@unina2.it 
can increase the degree of hyperandrogenism and its related clinical symptoms and signs. ${ }^{18,19}$ Though the role of obesity is generally acknowledged, relatively little attention has been focused on its real impact on the patients' quality of life..$^{20}$ This condition can weigh heavily against the carrying out of daily work and social activities, thus causing a significant reduction in health-related quality-of-life (HRQoL) in young patients. ${ }^{21-23}$ HRQoL represents a multidimensional index of physical, psychological, and social aspects associated with a specific pathology. The aim of this study was to evaluate how PCOS alone affects the quality of life and to assess to what extent obesity negatively influences it. In other words, this study evaluated the impact that the specific association between PCOS and obesity has on HRQoL.

\section{Materials and methods}

All recruited patients met the Rotterdam criteria of European Society of Human Reproduction and Embryology, American Society for Reproductive Medicine-sponsored PCOS Consensus Workshop Group (2003). ${ }^{24}$ Participants were provided with both written and oral information regarding the study protocol and were informed that they were free to withdraw from the study at any time. All subjects gave their written informed consent before participation. All procedures conformed to the directives of the Declaration of Helsinki. This study has been approved by the Azienda Universitaria Policlinico of the Second University of Naples. We recruited 100 Mediterranean women with PCOS aged 17.2-29 years divided into the following groups: (mean age: $23.1 \pm 5.9$ years) (group A) 50 with a body mass index $(\mathrm{BMI})>25 \mathrm{~kg} / \mathrm{m}^{2}$ (group $\mathrm{A}_{1}$; aged $22.8 \pm 5.6$ years; BMI: $31.6 \pm 5.8 \mathrm{~kg} / \mathrm{m}^{2}$ ) and 50 with a $\mathrm{BMI}<25 \mathrm{~kg} / \mathrm{m}^{2}$ (group $\mathrm{A}_{2}$; aged $23.3 \pm 6.1$ years; BMI: $22.3 \pm 1.6 \mathrm{~kg} / \mathrm{m}^{2}$ ). The patients were compared with a healthy normal-weight control group of 40 patients ranging from 16.4 to 31.8 years, who were age-matched and had a similar

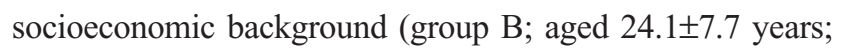
BMI: $22.0 \pm 2.1 \mathrm{~kg} / \mathrm{m}^{2}$ ). Another control group of 40 obese healthy women aged from 17.1 to 29.5 years (group C; aged $23.3 \pm 6.2$ years; BMI: $28.4 \pm 2.2 \mathrm{~kg} / \mathrm{m}^{2}$ ) was used to make a comparison with PCOS obese patients $\left(\mathrm{A}_{1}\right)$ to establish to what extent the worsening of quality of life can be ascribed to PCOS alone and to what, instead, it can be ascribed to an elevated BMI. These patients were administered the following questionnaires with the aim of evaluating the impact of the clinical spectrum of PCOS on HRQoL: ${ }^{25}$

\section{Symptom Checklist 90-Revised (SCL-90-R)}

It includes 90 items grouped into 10 main domains: Somatization (SOM), Obsessive-Compulsive (O-C), Interpersonal
Sensitivity (INT), Depression (DEP), Anxiety (ANX), Aggression (HOS), Phobia (PHOB), Paranoid Ideation (PAR), Psychoticism (PSY), and Sleep Disorders (SLEEP). To each question of a single domain can be attributed a score from 0 (not at all) to 4 (very much). Higher scores are indicative of worse conditions.

\section{6-Item Short-Form Health Survey (SF 36)}

It is a generic questionnaire used to evaluate HRQoL, the activity level, and the feeling of individual well-being. It consists of 36 items organized into eight domains: Physical Function (AF), Physical Role Function (RF), Bodily Pain (BP), General Health (GH), Vitality (VT), Social Function (SF), Emotional Role Function (RE), and Mental Health (SM) as well as an item on the change of General Health. The scores of each domain have been converted into a scale from 0 to 100 . Lower scores are indicative of worse conditions.

\section{Polycystic Ovary Syndrome Questionnaire (PCOSQ)}

A specific questionnaire used to outline the impact of the symptoms and signs of PCOS on HRQoL and whose proprieties were previously validated. ${ }^{26}$ PCOSQ contains 26 items organized into five domains: Emotions (EMOT), Hirsutism (HIRS), Body Weight (BW), Infertility (INF), and Menstrual Disorders (MD). In addition, for the present study, an "acne" domain with four different items useful to reinforce the usefulness of PCOSQ was also included. ${ }^{27} \mathrm{~A}$ score from 1 (always) to 7 (never) has been attributed to each question. Lower scores are indicative of more serious conditions. An arbitrary threshold of three was fixed, and the patient was considered "seriously" affected in the domains in which they scored above 3 .

Pearson's coefficient was used to interpret the correlation between BMI and each of the test domains. The Student's $t$-test was used to verify the significance of the differences in the main score for each domain between PCOS and healthy group (A vs B), PCOS obese and PCOS lean patients $\left(A_{1}\right.$ vs $\left.A_{2}\right)$, and, finally, PCOS obese patients and healthy obese controls $\left(A_{1} v s\right)$. The level of significance was fixed, in all the cases, at 0.05 .

\section{Results}

SCL-90-R revealed significantly elevated scores in PCOS patients (A) compared with controls (B) in three symptomatic dimensions: O-C (A: $0.7 \pm 0.5$; B: $0.3 \pm 0.3 ; P<0.001)$, DEP (A: $0.9 \pm 0.4$; B: $0.7 \pm 0.5 ; P=0.03$ ), and ANX (A: $0.7 \pm 0.4$; B: $0.4 \pm 0.3 ; P=0.003$ ) (Figure 1). In addition, there was a 


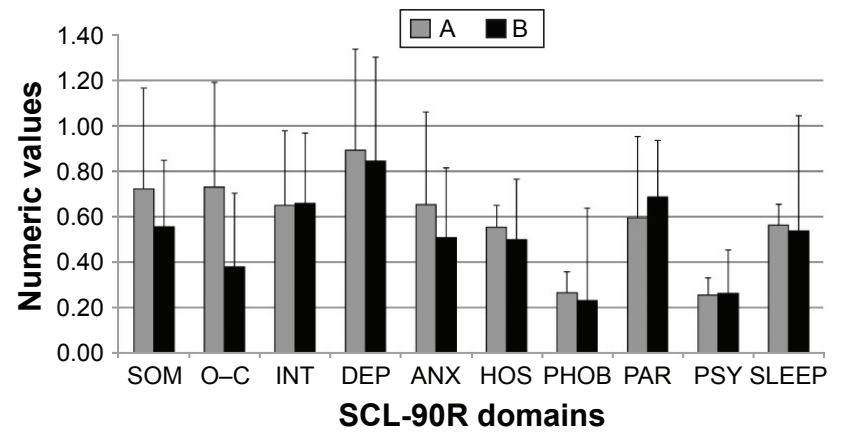

Figure I SCL-90-R in PCOS patients (A) and healthy normal-weight controls (B). Note: Values are expressed as mean \pm standard deviation.

Abbreviations: PCOS, polycystic ovary syndrome; SCL-90-R, Symptom Checklist 90-Revised; SOM, somatization; O-C, obsessive-compulsive; INT, interpersonal sensitivity; DEP, depression; ANX, anxiety; HOS, aggression; PHOB, phobia; PAR, paranoid ideation; PSY, psychoticism; SLEEP, sleep disorders.

positive correlation between BMI and 1) SOM $(P<0.001)$, confirmed also by Student's $t$-test $\left(\mathrm{A}_{1}: 0.8 \pm 0.5 ; \mathrm{A}_{2}: 0.6 \pm 0.3\right.$; $P=0.03)$; 2) INT $(P<0.001)$, confirmed also by Student's $t$-test $\left(\mathrm{A}_{1}: 0.7 \pm 0.3 ; \mathrm{A}_{2}: 0.6 \pm 0.3 ; P=0.02\right)$; and 3$) \mathrm{PAR}$ $(P<0.001)$, confirmed also by Student's $t$-test $\left(\mathrm{A}_{1}: 0.8 \pm 0.4\right.$; $\mathrm{A}_{2}: 0.5 \pm 0.1 ; P<0.001$ ) (Figure 2). Finally, the comparison between healthy obese women $(\mathrm{C})$ and PCOS obese patients $\left(\mathrm{A}_{1}\right)$ revealed higher scores in the latter in the following domains: SOM $\left(\mathrm{A}_{1}: 0.8 \pm 0.5 ; \mathrm{C}: 0.6 \pm 0.3 ; P<0.05\right)$, O-C $\left(\mathrm{A}_{1}: 0.8 \pm 0.5 ; \mathrm{C}: 0.4 \pm 0,1 ; P<0.001\right), \mathrm{ANX}\left(\mathrm{A}_{1}: 0.7 \pm 0.5\right.$; $\mathrm{C}: 0.5 \pm 0.1 ; P=0.005), \operatorname{HOS}\left(\mathrm{A}_{1}: 0.6 \pm 0.1 ; \mathrm{C}: 0.5 \pm 0.1\right.$; $P<0.001)$, PHOB $\left(\mathrm{A}_{1}: 0.3 \pm 0.1 ; \mathrm{C}: 0.2 \pm 0.2 ; P=0.05\right)$, and INT $\left(\mathrm{A}_{1}: 0.6 \pm 0.1 ; \mathrm{C}: 0.5 \pm 0.2 ; P<0.001\right)$.

With regard to SF36, it was shown that PCOS patients (A), compared with healthy controls (B), had decreased scores, indicating lower quality of life, in the domains of VT (A: $53.4 \pm 12.1 ; \mathrm{B}: 65.2 \pm 2.5 ; P<0.001)$, RE (A: 52.3 \pm 27.6 ; B: $75.6 \pm 6.1 ; P<0.001$ ), SM (A: 47.5 \pm 13.7 ;

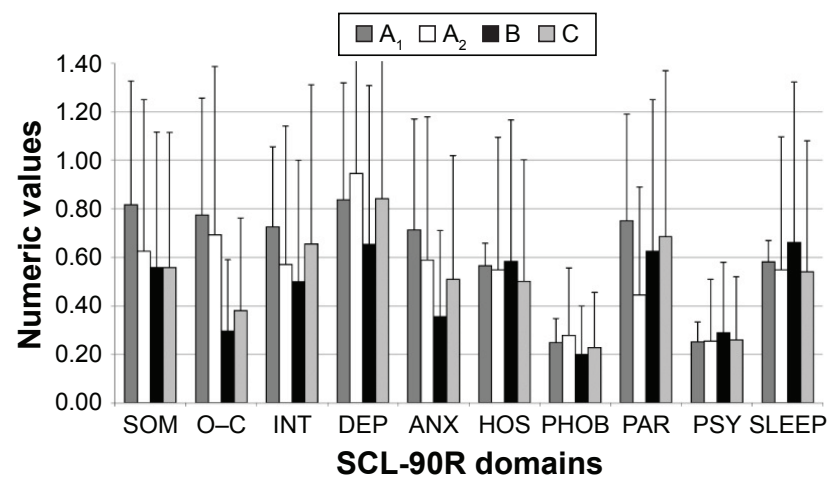

Figure 2 SCL-90-R in PCOS obese patients $\left(A_{1}\right)$, PCOS normal-weight patients $\left(A_{2}\right)$, normal-weight healthy controls $(B)$, and healthy obese controls $(C)$.

Note: Values are expressed as mean \pm standard deviation.

Abbreviations: PCOS, polycystic ovary syndrome; SCL-90-R, Symptom Checklist 90-Revised; SOM, somatization; O-C, obsessive-compulsive; INT, interpersonal sensitivity; DEP, depression; ANX, anxiety; HOS, aggression; PHOB, phobia; PAR, paranoid ideation; PSY, psychoticism; SLEEP, sleep disorders.

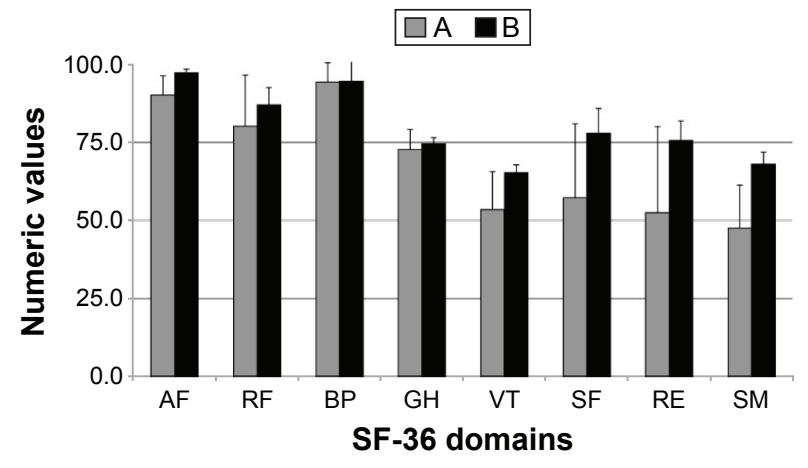

Figure 3 SF-36 in PCOS patients (A) and healthy normal-weight controls (B). Note: Values are expressed as mean \pm standard deviation.

Abbreviations: PCOS, polycystic ovary syndrome; SF-36, 36-Item Short-Form Health Survey; AF, physical function; RF, physical role function; BP, bodily pain; $\mathrm{GH}$, general health; VT, vitality; SF, social function; RE, emotional role function; SM, mental health.

B: $68.0 \pm 3.9 ; P<0.001)$, SF (A: $57.1 \pm 23.8 ; \mathrm{B}: 77.8 \pm 8.0$; $P<0.001$ ), and AF (A: 90.1 $\pm 6.2 ; \mathrm{B}: 97.3 \pm 1.2 ; P<0.001$ ). No significant difference was found in the domains of $\mathrm{RF}$ (A: $80.1 \pm 16.3$; B: $86.9 \pm 5.5 ; P=0.07$ ), GH (A: 72.6 \pm 6.5 ; B: $74.9 \pm 1.6 ; P=0.11$ ), and BP (A: $94.1 \pm 6.2$; B: 95.0 \pm 7.4 ; $P=0.802$ ) (Figure 3 ). In addition, there was a positive correlation between BMI and 1) AP $(P<0.001)$, confirmed also by Student's $t$-test $\left(\mathrm{A}_{1}: 85.9 \pm 5.5 ; \mathrm{A}_{2}: 94.2 \pm 3.4 ; P<0.001\right)$ and 2) SF $(P<0.001)$, confirmed also by Student's $t$-test $\left(\mathrm{A}_{1}: 48.5 \pm 22.4 ; \mathrm{A}_{2}: 65.8 \pm 21.9 ; P<0.001\right.$ ) (Figure 4). Finally, the comparison between healthy obese women $(\mathrm{C})$ and PCOS obese patients $\left(\mathrm{A}_{1}\right)$ revealed higher scores in the latter group in the following domains: $\mathrm{AF}\left(\mathrm{A}_{1}: 85.9 \pm 5.5\right.$; C: $88.8 \pm 3.3 ; P<0.001)$, VT (A $: 54.3 \pm 10.6$; $: 60.0 \pm 5.0$; $P=0.001), \operatorname{RE}\left(\mathrm{A}_{1}: 49.3 \pm 22.4 ; \mathrm{C}: 63.2 \pm 13.1 ; P<0.0001\right)$, and $\mathrm{SM}\left(\mathrm{A}_{1}: 45.7 \pm 12.9 ; \mathrm{C}: 51.7 \pm 3.6 ; P=0.005\right)$.

PCOS patients (A), compared with controls (B), had significantly lower scores in PCOSQ in the domains of: EMOT

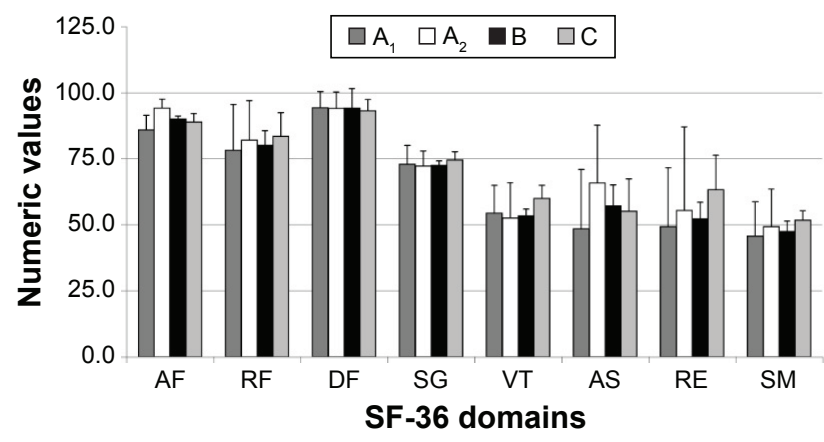

Figure 4 SF-36 in PCOS obese patients $\left(A_{1}\right)$, PCOS normal-weight patients $\left(A_{2}\right)$, lean normal-weight healthy controls (B), and healthy obese controls (C). Note: Values are expressed as mean \pm standard deviation.

Abbreviations: PCOS, polycystic ovary syndrome; SF-36, 36-Item Short-Form Health Survey; AF, physical function; RF, physical role function; VT, vitality; RE, emotional role function; SM, mental health; DF, emotional well-being; SG, social functioning; AS, health change. 


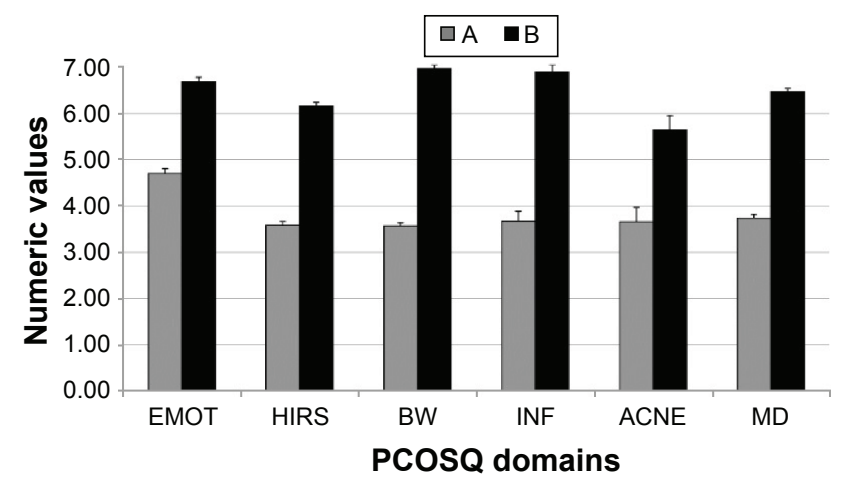

Figure 5 PCOSQ in PCOS patients (A) and healthy normal-weight controls (B). Note: Values are expressed as mean \pm standard deviation.

Abbreviations: PCOS, polycystic ovary syndrome; PCOSQ, Polycystic Ovary Syndrome Questionnaire; EMOT, emotions; HIRS, hirsutism; BW, body weight; INF, infertility; MD, menstrual disorders.

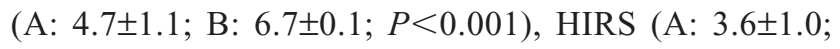
B: $6.2 \pm 0.1 ; P<0.001)$ BW (A: $3.6 \pm 1.2 ; \mathrm{B}: 7.0 \pm 0.1 ; P<0.001)$, INF (A: 3.7 $\pm 1.1 ; \mathrm{B}: 6.9 \pm 0.2 ; P<0.001$ ), $\operatorname{ACNE}(\mathrm{A}: 3.7 \pm 1.0$; B: $5.6 \pm 0.3 ; P<0.001$ ), and MD (A: 3.7 $\pm 1.0 ; \mathrm{B}: 6.5 \pm 0.1$; $P<0.001)$ (Figure 5). In addition, there was a positive correlation between BMI and 1) EMOT $(P<0.001)$, confirmed also by Student's $t$-test $\left(\mathrm{A}_{1}: 4.5 \pm 1.1 ; \mathrm{A}_{2}: 4.9 \pm 0.9\right.$; $P<0.001)$; 2) BW ( $P<0.001)$, confirmed also by Student's $t$-test $\left(\mathrm{A}_{1}: 3.2 \pm 1.1 ; \mathrm{A}_{2}: 3.9 \pm 1.1 ; P<0.001\right)$; and 3$) \mathrm{ACNE}$ $(P<0.01)$, confirmed also by Student's $t$-test $\left(\mathrm{A}_{1}: 3.4 \pm 1.0\right.$; $\mathrm{A}_{2}: 3.9 \pm 1.0 ; P=0.03$ ) (Figure 6). Having set the pathological threshold of the mean score at 3 , the most frequently affected domains were BW (22\%), Hirs (19\%), Emot (18\%), Acne (18\%), Inf (17\%), and MD (17\%). Finally, the comparison between healthy obese women (C) and PCOS obese patients $\left(\mathrm{A}_{1}\right)$ revealed higher scores in the latter group in all the domains of the test: EMOT $\left(\mathrm{A}_{1}: 4.5 \pm 1.1\right.$; $\mathrm{C}: 4.9 \pm 0.9$;

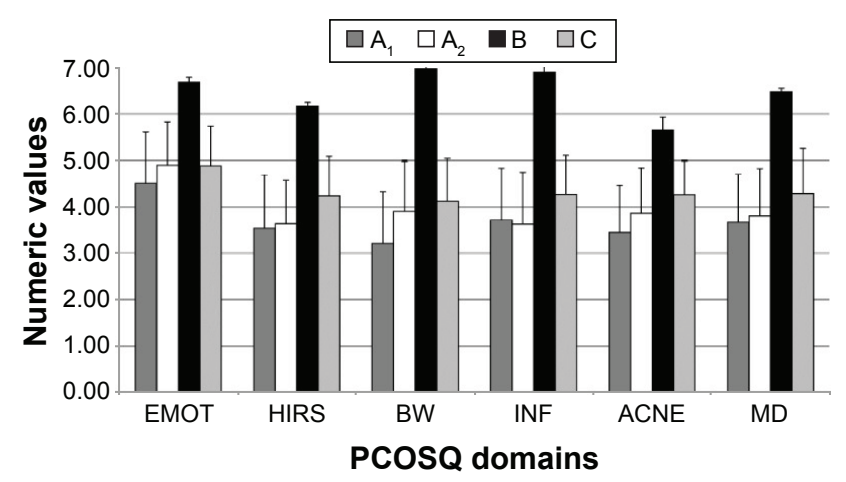

Figure 6 PCOSQ in PCOS obese patients $\left(A_{1}\right)$, PCOS normal-weight patients $\left(A_{2}\right)$, normal-weight healthy controls (B), and healthy obese controls (C).

Note: Values are expressed as mean \pm standard deviation.

Abbreviations: PCOS, polycystic ovary syndrome; PCOSQ, Polycystic Ovary Syndrome Questionnaire; EMOT, emotions; HIRS, hirsutism; BW, body weight; INF, infertility; MD, menstrual disorders.
$P<0.05)$, HIRS (A: $: 3.5 \pm 1.2 ; \mathrm{C}: 4.2 \pm 0.9 ; P<0.002)$, BW $\left(\mathrm{A}_{1}: 3.2 \pm 1.1 ; \mathrm{C}: 4.1 \pm 0.9 ; P<0.0001\right), \mathrm{INF}\left(\mathrm{A}_{1}: 3.7 \pm 1.1 ; \mathrm{C}\right.$ : $4.3 \pm 0.8 ; P=0.003), \mathrm{MD}\left(\mathrm{A}_{1}: 3.7 \pm 1.0 ; \mathrm{C}: 4.3 \pm 1 ; P=0.001\right)$, and ACNE (A: $3.4 \pm 1.0 ; \mathrm{C}: 4.2 \pm 0.7 ; P<0.0001)$. A positive correlation $(P<0.05)$ was found between $\mathrm{BMI}$ and all the domains of SF-36, SCL-90-R, and PCOSQ in the PCOS group (A) and in the control healthy group (B), whereas in the healthy obese group $(\mathrm{C})$ a positive correlation of BMI was revealed only with BP and SM of SF-36, SOM, and PSY of SCL-90-R and none of the PCOSQ domains.

\section{Discussion}

PCOS, characterized by phenotypic heterogeneity and a wide variety of long-term metabolic and cardiovascular complicances ${ }^{28}$ is an important cause of severe distress. In fact, hirsutism causes considerable psychological distress confirmed by psychometric evaluation, which reveals marked anxiety and social discomfort; ${ }^{29}$ infertility causes family tensions and problems at work, while obesity in PCOS women is responsible for a general state of depression and dissatisfaction. ${ }^{30,31}$ An important study made by Cronin reported that the main problems for the women affected by PCOS were hirsutism (90\%), being overweight (84\%), menstrual disorders $(82 \%)$, and difficulties maintaining their body weight $(80 \%))^{32,33}$

This study focuses on a Mediterranean population assessed using SCL-90-R, SF-36, and PCOSQ, correlating, for every group, the test scores with BMI. Psychological disturbances, measured by SCL-90-R, strongly influence global well-being. In particular, in PCOS patients (A), the $\mathrm{O}-\mathrm{C}, \mathrm{DEP}$, and ANX dimensions were considerably affected independently of BMI, as reported in other studies. ${ }^{34,35}$ Among the main causes of depression and anxiety is probably the dissatisfaction with the body image or womanly identity. Obese patients $\left(A_{1}\right)$, moreover, showed significant changes in the dimensions of SOM, INT, and PAR, probably because they showed a more serious phenotypic expression of PCOS and so had difficulty in establishing relations and showed a severe antisocial attitude that could lead to a much greater tendency to somatization. The analysis of SCL-90-R showed that being overweight or obese was not the only determining factor, as demonstrated by the distortion of many domains even in women with normal BMI. HRQoL result worsened also when was evaluated with SF-36. In particular, the domains more significantly affected in the PCOS sample were VT, RE, MH, SF, and AP. This finding suggests that PCOS, regardless of BMI, determines a relevant impairment of psychosocial functions. The domains 
of SF and AP, however, were significantly more affected in patients with $\mathrm{BMI}>25\left(\mathrm{~A}_{1}\right)$ compared with controls $(\mathrm{B})$. This is in-line with other studies, which also have shown that BMI in the SF-36 is a physical score predictor. ${ }^{36,37}$ In our study, however, no significant difference was found for the scales of RF, BP, and GH. However, PCOSQ appeared the most sensitive test for the evaluation of HRQoL, and it can provide a lot of information on the causes of psychological distress. PCOSQ identifies weight gain as one of the most important causes of distress in PCOS patients. In particular, PCOS obese patients $\left(\mathrm{A}_{1}\right)$, compared with nonobese ones $\left(\mathrm{A}_{2}\right)$, showed a further increase in scores in the domain of BW, ACNE, and EMOT, which emphasizes how the association between PCOS and overweight/obesity can cause a severe worsening of the emotional and the physical domains. The main domains involved were BW (22\%) and HIRS (19\%), as reported in other studies, ${ }^{38,39}$ followed by EMOT and ACNE (both 18\%), and INF and MD (both $17 \%$ ). It is important to note that infertility, one of the main malfunctions related to $\mathrm{PCOS},{ }^{40-42}$ proved to be a minor determinant in this study. The reason for this contrasting finding may be the younger age of our sample - a time when maternity is not considered a priority yet. However, the BMI is not the only determinant of worsening of quality of life in PCOS patients, given that from the comparison between PCOS obese women $\left(\mathrm{A}_{1}\right)$ and obese controls $(\mathrm{C})$, emerged a significant alteration in a lot of the domains: AF, VT, RE, SM (SF-36), SOM, O-C, ANX, HOS, PHOB, SLEEP (SCL-90-R), and in all of the PCOSQ domains. This evidence suggests that PCOS by itself makes worse the quality of life, whereas obesity, when it is present, configures itself as a pejorative element.

Therefore, given that PCOS is an important cause of psychic distress, ${ }^{43}$ it would be necessary to carry out a psychological screening by making use of HRQoL measurements, ${ }^{44-46}$ besides the routine physical, laboratory, and instrumental examinations, in order to evaluate the fragile psychological balance of these women. We believe that PCOSQ is the most sensitive test to evaluate HRQoL in PCOS patients, as highlighted by the evidence that the differences between the groups studied with PCOSQ were more markedly significant than the ones that emerged from the analysis of the scores obtained from other tests.

The general aim of any treatment is to reach a state of "good health", which, according to World Health Organization, coincides with the concept of psychophysical well-being and implies a healthy perception of our body and a good relation with ourselves. ${ }^{47-50}$ The restoration of psychophysical well-being is, therefore, the main objective of a proper treatment of PCOS; so this endocrinopathy requires an approach aimed at improving the quality of life and self-perception as well as the symptoms of the disease. Particularly, special care is needed by obese PCOS patients, because their more severe phenotype exposes them to a greater risk of developing serious psychic distress.

\section{Conclusion}

In conclusion, the results from our study confirmed the negative impact of PCOS on the patients' quality of life and particularly highlighted how obesity contributes to its phenotypic spectrum, thus becoming an important pejorative element.

\section{Acknowledgment}

This research did not receive any specific grant from any funding agency in the public, commercial or not-for-profit sector.

\section{Author contributions}

Annalisa Panico and Giovanni Messina contribute equally to the article. Giovanni Messina and Antonietta Messina are second-degree relatives. Gelsy Arianna Lupoli, Roberta Lupoli, and Giovanni Lupoli are first-degree relatives. Vincenzo Monda and Marcellino Monda are first-degree relatives. All authors contributed toward data analysis, drafting and critically revising the paper and agree to be accountable for all aspects of the work.

\section{Disclosure}

The authors reports no conflicts of interests in this work.

\section{References}

1. Barber TM, McCarthy MI, Wass JAH, Franks S. Obesity and polycystic ovary syndrome. Clin Endocrinol (Oxf). 2006;65(2):137-145.

2. Norman RJ, Dewailly D, Legro RS, Hickey TE. Polycystic ovary syndrome. Lancet (London, England). 2007;370(9588):685-697.

3. Carmina E, Azziz R. Diagnosis, phenotype, and prevalence of polycystic ovary syndrome. Fertil Steril. 2006;86(Suppl 1):S7-S8.

4. Guzick DS. Do cardiovascular risk factors in polycystic ovarian syndrome result in more cardiovascular events? J Clin Endocrinol Metab. 2008;93(4):1170-1171.

5. Viggiano A, Vicidomini C, Monda M, et al. Fast and low-cost analysis of heart rate variability reveals vegetative alterations in noncomplicated diabetic patients. J Diabetes Complications. 2009;23(2):119-123.

6. Witchel SF, Roumimper H, Oberfield S. Polycystic ovary syndrome in adolescents. Endocrinol Metab Clin North Am. 2016;45(2): 329-344.

7. Rosenfield RL. The diagnosis of polycystic ovary syndrome in adolescents. Pediatrics. 2015;136(6):1154-1165.

8. Chieffi S, Iachini T, Iavarone A, Messina G, Viggiano A, Monda M. Flanker interference effects in a line bisection task. Exp Brain Res. 2014;232(4): $1327-1134$ 
9. Verrotti A, Agostinelli S, D'Egidio C, et al. Impact of a weight loss program on migraine in obese adolescents. Eur J Neurol. 2013;20(2): 394-397.

10. Carotenuto M, Santoro N, Grandone A, et al. The insulin gene variable number of tandemrepeats (INS VNTR) genotype and sleep disordered breathing in childhood obesity. J Endocrinol Invest. 2009; 32(9):752-755.

11. Carotenuto M, Bruni O, Santoro N, del Giudice EM, Perrone L, Pascotto A. Waist circumference predicts the occurrence of sleep-disordered breathing in obese children and adolescents: a questionnaire-based study. Sleep Med. 2006;7(4):357-361.

12. Messina G, Monda V, Moscatelli F, et al. Role of orexin in obesity system, biology and medicine. Biol Med. 2015;7(4):1000248.

13. Hung JH, Hu LY, Tsai SJ, et al. Risk of psychiatric disorders following polycystic ovary syndrome: a nationwide population-based cohort study. PLoS One. 2014;9(5):7-12.

14. Tock L, Carneiro G, Togeiro SM, et al. Obstructive sleep apnea predisposes to nonalcoholic fatty liver disease in patients with polycystic ovary syndrome. Endocr Pract. 2014;20(3):244-251.

15. Shreeve N, Cagampang F, Sadek K, et al. Poor sleep in PCOS; is melatonin the culprit? Hum Reprod. 2013;28(5):1348-1353.

16. Stanley T, Misra M. Polycystic ovary syndrome in obese adolescents. Curr Opin Endocrinol Diabetes Obes. 2008;15(1):30-36.

17. Viggiano A, Nicodemo U, Viggiano E, et al. Mastication overload causes an increase in O2-production into the subnucleus oralis of the spinal trigeminal nucleus. Neuroscience. 2010;166(2):416-421.

18. Goodarzi MO, Dumesic DA, Chazenbalk G, Azziz R. Polycystic ovary syndrome: etiology, pathogenesis and diagnosis. Nat Rev Endocrinol. 2011;7(4):219-231.

19. Messina G, Dalia C, Tafuri D, et al. Orexin-A controls sympathetic activity and eating behavior. Front Psychol. 2014;5:997.

20. Esposito M, Gallai B, Roccella M, et al. Anxiety and depression levels in prepubertal obese children: a case - control study. Neuropsychiatr Dis Treat. 2014;10:1897-1902.

21. Jones GL, Hall JM, Balen AH, Ledger WL. Health-related quality of life measurement in women with polycystic ovary syndrome: a systematic review. Hum Reprod Update. 2008;14(1):15-25.

22. Moscatelli F, Messina G, Valenzano A, et al. Differences in corticospinal system activity and reaction response between karate athletes and non-athletes. Neurol Sci. 2016;37(12):1947-1953.

23. Viggiano A, Chieffi S, Tafuri D, Messina G, Monda M, De Luca B. Laterality of a second player position affects lateral deviation of basketball shooting. J Sports Sci. 2014;32(1):46-52.

24. Rotterdam ESHRE/ASRM-Sponsored PCOS Consensus Workshop Group. Revised 2003 consensus on diagnostic criteria and longterm health risks related to polycystic ovary syndrome. Fertil Steril. 2004;81(1):19-25. Available from: http://www.ncbi.nlm.nih.gov/ pubmed/14711538

25. Coffey S, Bano G, Mason HD. Health-related quality of life in women with polycystic ovary syndrome: a comparison with the general population using the Polycystic Ovary Syndrome Questionnaire (PCOSQ) and the Short Form-36 (SF-36). Gynecol Endocrinol. 2006;22(2):80-86.

26. Jones GL, Benes K, Clark TL, et al. The Polycystic Ovary Syndrome Health-Related Quality of Life Questionnaire (PCOSQ): a validation. Hum Reprod. 2004;19(2):371-377. Available from: http://www.ncbi. nlm.nih.gov/pubmed/14747184

27. Moscatelli F, Valenzano A, Petito A, et al. Relationship between blood lactate and cortical excitability between taekwondo athletes and non-athletes after hand-grip exercise. Somatosens Mot Res. 2016;33(2):137-144.

28. Azziz R, Woods KS, Reyna R, Key TJ, Knochenhauer ES, Yildiz BO. The prevalence and features of the polycystic ovary syndrome in an unselected population. J Clin Endocrinol Metab. 2004;89:2745-2749.

29. Moscatelli F, Messina G, Valenzano A, et al. Functional assessment of corticospinal system excitability in karate athletes. PLoS One. 2016; 11(5):e0155998.
30. Paulson JD, Haarmann BS, Salerno RL, Asmar P. An investigation of the relationship between emotional maladjustment and infertility. Fertil Steril. 1988;49(2):258-262.

31. Himelein MJ, Thatcher SS. Depression and body image among women with polycystic ovary syndrome. J Health Psychol. 2006;11(4):613-625.

32. Cronin L, Guyatt G, Griffith L, et al. Development of a health-related quality-of-life questionnaire (PCOSQ) for women with polycystic ovary syndrome (PCOS). J Clin Endocrinol Metab. 1998;83(6):1976-1987.

33. Di Bernardo G, Messina G, Capasso S, et al. Sera of overweight people promote in vitro adipocyte differentiation of bone marrow stromal cells. Stem Cell Res Ther. 2014;5(1):4.

34. Elsenbruch S, Hahn S, Kowalsky D, et al. Quality of life, psychosocial well-being, and sexual satisfaction in women with polycystic ovary syndrome. J Clin Endocrinol Metab. 2003;88(12):5801-5807.

35. Monda M, Messina G, Scognamiglio I, et al. Short-term diet and moderate exercise in young overweight men modulate cardiocyte and hepatocarcinoma survival by oxidative stress. Oxid Med Cell Longev. 2014;2014(3):1-7.

36. Hahn S, Janssen OE, Tan S, et al. Clinical and psychological correlates of quality-of-life in polycystic ovary syndrome. Eur J Endocrinol. 2005; 153(6):853-860.

37. Messina G, Di Bernardo G, Viggiano A. Exercise increases the level of plasma orexin A in humans. J Basic Clin Physiol Pharmacol. 2016;27(6): 611-616.

38. Pekhlivanov B, Kolarov G, Kavurdzhikova S, Stoikov S. [Determinants of health related quality of life in women with polycystic ovary syndrome]. Akush Ginekol (Sofiia). 2006;45(7):29-34.

39. Chieffi S, Iavarone A, Iaccarino L, et al. Age-related differences in distractor interference on line bisection. Exp Brain Res. 2014;232(11): 3659-3664.

40. Tan S, Hahn S, Benson S, et al. Psychological implications of infertility in women with polycystic ovary syndrome. Hum Reprod. 2008;23(9): 2064-2071.

41. McCook JG, Reame NE, Thatcher SS. Health-related quality of life issues in women with polycystic ovary syndrome. J Obstet Gynecol Neonatal Nurs. 2005;34(1):12-20.

42. Monda M, Messina G, Mangoni C, et al. Resting energy expenditure and fat-free mass do not decline during aging in severely obese women. Clin Nutr. 2008;27(4):657-659.

43. Pasch L, He SY, Huddleston H, et al. Clinician vs self-ratings of hirsutism in patients with polycystic ovarian syndrome: associations with quality of life and depression. JAMA Dermatol. 2016;152(7):783-788.

44. Lin CY, Ou HT, Wu MH, Chen PC. Validation of Chinese version of Polycystic Ovary Syndrome Health-Related Quality of Life Questionnaire (Chi-PCOSQ). PLoS One. 2016;11(4):e0154343.

45. Messina G, De Luca V, Viggiano A, et al. Autonomic nervous system in the control of energy balance and body weight: personal contributions. Neurol Res Int. 2013;2013:639280.

46. Monda M, Viggiano A, De Luca V. Haloperidol reduces the sympathetic and thermogenic activation induced by orexin A. Neurosci Res. 2003;45(1):17-23.

47. Monda M, Viggiano A, Viggiano A, et al. Sympathetic and hyperthermic reactions by orexin A: role of cerebral catecholaminergic neurons. Regul Pept. 2007;139(1-3):39-44.

48. Valenzano A, Moscatelli F, Triggiani AI, et al. Heart-rate changes after an ultraendurance swim from Italy to Albania: a case report. Int J Sports Physiol Perform. 2016;11(3):407-409.

49. Messina G, Palmieri F, Monda V, et al. Exercise causes muscle GLUT4 translocation in an insulin-independent manner. Biol Med. 2015;1(2):1-4.

50. Moscatelli F, Messina G, Valenzano A, et al. Relationship between RPE and blood lactate after fatiguing handgrip exercise in taekwondo and sedentary subjects. Biol Med. 2015;1:S3008. 
Patient Preference and Adherence

Dovepress

\section{Publish your work in this journal}

Patient Preference and Adherence is an international, peer-reviewed, open access journal that focuses on the growing importance of patient preference and adherence throughout the therapeutic continuum. Patient satisfaction, acceptability, quality of life, compliance, persistence and their role in developing new therapeutic modalities and compounds to optimize

Submit your manuscript here: http://www.dovepress.com/patient-preference-and-acherence-journa clinical outcomes for existing disease states are major areas of interest for the journal. This journal has been accepted for indexing on PubMed Central. The manuscript management system is completely online and includes a very quick and fair peer-review system, which is all easy to use. Visit http://www. dovepress.com/testimonials.php to read real quotes from published authors. 